\title{
Nonstationary extreme value analysis of temperature extremes in China
}

\author{
Meng Gao ${ }^{1}$ Hongzhen Zheng ${ }^{1,2}$
}

Published online: 30 October 2017

(C) Springer-Verlag GmbH Germany 2017

\begin{abstract}
In a changing climate, the common assumption of stationarity of climate extremes has been increasingly challenged, raising the need to incorporate non-stationarity in extreme value modeling. In this study, quantile regression is used to identify the trends of annual temperature extremes and their correlations with two large climate patterns, the western Pacific subtropical high (WPSH) and the Arctic Oscillation (AO) at 357 stations in China. Statistical significant positive trends and correlations between warm (or cold) temperature extremes and WPSH (or AO) have been detected at most stations. The influence of WPSH on warm extremes is significant in southern China, while the AO mainly affects the cold extremes in northern and eastern China. Then, annual temperature extremes are fitted to generalized extreme value (GEV) distributions with time-varying parameters. The summer (or winter) mean daily maximum (or minimum) temperatures and two climate indices, the WPSH index and the AO index, are chosen as covariates. In total, 16 candidate GEV distribution models are constructed, and the best fitting model with the lowest Bayesian information criterion (BIC) is selected. The 20-year return levels of annual warm (or cold) extremes in the period 1961-1980 and 1991-2010 are computed and compared. The changes of 20 -year return levels of annual warm and cold extremes are jointly determined by trend and distributional changes of annual temperature extremes. Analysis of large scale atmospheric
\end{abstract}

Meng Gao

mgao@yic.ac.cn; gaomeng03@hotmail.com

1 Yantai Institute of Coastal Zone Research, CAS, No.17,Chunhui Road, Yantai 264003, China

2 University of Chinese Academy of Sciences, Beijing 100049, China circulation changes indicate that a strengthening anticyclonic circulation and increasing geopotential height in recent decades may have contributed to the changes in temperature extremes in China.

Keywords Temperature extremes · GEV $\cdot$ Nonstationarity $\cdot$ Return level $\cdot$ Atmospheric circulation

\section{Introduction}

Climate change and global warming, especially changes in climate extremes, have attracted wide concerns in recent years (Kharin et al. 2007; Zhang and Zwiers 2013). In IPCC's Fourth Assessment Report, a much greater effort had been made in analyzing change in climate extremes (IPCC 2007). Later, IPCC defined climate extreme as the occurrence of a weather or climate variable above (or below) a threshold value near the upper (or lower) ends of the range of observed values of the variable (IPCC 2012). A warming climate has been shown to exacerbate and trigger certain climate extremes, including extreme high temperatures, decreasing the frequency of extreme low temperatures, and increasing intense precipitation events (Easterling et al. 2000; IPCC 2007). It is therefore important to detect the changes in climate extremes and identify their connections to global climate change.

In the past two decades, many analyses have been conducted on long-term change of climate extremes. These analyses were using either various climate extremes indices (Alexander et al. 2006; Tebaldi et al. 2006) or statistical extreme value method (Kharin et al. 2007; Brown et al. 2008). The Expert Team on Climate Change Detection and Indices (ETCCDI) defined as many as 27 indices for extreme weather and climate events including 16 indices 
for temperature extremes and 11 indices for precipitation extremes. These 27 indices could be further classified into five categories including percentile-based and absolute indices, as well as other kinds of indices (Alexander et al. 2006). According to extreme value theory, climate extremes could also be expressed in terms of $T$-year return values of annual extremes of climate or weather variables, which are of importance to engineering design and planning (Kharin et al. 2007, 2013).

For a long time, the fundamental probability theory of extreme values has been well developed (Leadbetter 1983; Katz 2013; Salas and Obeysekera 2014). Generally, extreme events are assumed to be temporally stationary, which could be characterized by probability distributions such as the generalized extreme value (GEV) distribution and generalized Pareto (GP) distribution (Coles 2001; Li et al. 2013; Jahanbaksh Asl et al. 2011; Gao et al. 2016). As climate changed, the stationarity assumption in traditional climate extreme value analysis gradually became questionable (Milly et al. 2008; Wigley 2009; Cooley 2013; Katz 2013; Wi et al. 2016). It has been documented that in some places climatic and hydrological extremes exhibit some type of non-stationarity in the form of trends, shifts or a combination of them (Kiem et al. 2003; Villarini et al. 2009). To bring these nonstationary features into statistical extreme value modeling frameworks, alternative mathematical formulations are developed by allowing time-dependent parameters in probability density functions (pdfs) of extreme values (Khaliq et al. 2006; Katz 2010; Siliverstovs et al. 2010; Wi et al. 2016). The parameters in GEV or GP distributions could also be dependent on climate indices such as El Niño-Southern Oscillation (ENSO) and North Atlantic Oscillation (NAO) indices (Brown et al. 2008; Gao et al. 2016). Nonstationary extreme value distributions were found to be a powerful and useful tool in modeling climate extremes in a changing climate (Brown et al. 2008).

On global, regional and national scales, temperature extremes have been extensively studied (Frich et al. 2002; Aguilar et al. 2005; Alexander et al. 2006; Brown et al. 2008; Xu et al. 2011; You et al. 2011). These studies have shown that significant widespread changes in temperature extremes are associated with warming. Generally, temperature extremes include cold extremes and warm extremes, which both influence on ecosystems, economies and society. Extreme high temperatures, which deviate far from the normal temperatures, are considered to worsen many types of disasters, including heat waves, droughts, leading to increased population mortality (IPCC 2012). For example, heat waves occurred in summer of 2003 resulted in over 22,000 heat related deaths across Europe (Christoph and Gerd 2004). In addition, cold waves that occur in winter intermittently and also influence agriculture, transportation, and human health, and so on.

China has already experienced significant temperature changes during recent decades (Ding et al. 2007). The mean daily maximum and mean daily minimum air temperatures have increased at rates of 0.13 and $0.32^{\circ} \mathrm{C} /$ decade from 1955 to 2000, respectively (Wang and Gong 2000). The increasing trends in mean maximum temperatures have occurred in northern China, while weak decreasing or nonsignificant trends have occurred in southern China (Zhai and Pan 2003; You et al. 2011). Mean minimum temperatures have increased all over China (You et al. 2011; Zhang et al. 2011). To our best knowledge, most studies on changes in temperature extremes in China were conducted by detecting the trends of extreme temperature indices. However, nonstationary extreme value analysis method has been less often applied. Moreover, there is still a lack of understanding of temperature extremes in China and its connection with large scale atmospheric circulation such as the western Pacific subtropical high (WPSH) and the Arctic Oscillation (AO).

The WPSH is a large-scale anticyclonic circulation that occupies about one quarter of the Northern Hemispheric surface in summer and has significant influences on the East Asian summer climate (Huang et al. 2015). WPSH is quantified by WPSH index (WPSHI) that signifies the zonal and meridional variation of the location and intensity of the East Asian jet stream entrance region (Barnston and Livezey 1987). The AO is one of the dominant patterns of Northern Hemisphere climate variability, and it is most prevalent in winter and in the mid and high latitudes (Ramos et al. 2010; You et al. 2013). The daily AO index (AOI), which is constructed by projecting the daily (00Z) $1000 \mathrm{mb}$ height anomalies poleward of $20^{\circ} \mathrm{N}$ onto the loading pattern of the $\mathrm{AO}$, is used to quantify AO. Recent studies have shown that the winter AOI has a strong positive correlation with temperatures in northern China (Gong and Wang 2003; You et al. 2013). The main objective of this study is to investigate the nonstationary characteristics of temperature extremes in China and further exploring the influence of large scale atmospheric circulation patterns on the changes in temperature extremes.

In this study, quantile regression is used to detect changes of temperature extremes and correlations to the WPSH and the AO. Then, the year index and the two climate indices, WPSHI and AOI, are chosen as covariates in nonstationary GEV distributions, respectively. Then, the 20-year return levels of annual warm or cold extremes in the period 1961-1980 and 1991-2010 are computed and compared based on the best fitting GEV distribution model. Finally, relationships between large scale atmospheric 
circulation patterns and the changes in temperature extremes are discussed.

\section{Data}

The datasets of daily temperatures including maximum, mean and minimum temperatures are provided by the National Meteorological Information Center (NMIC) of China Meteorological Administration (CMA). There are totally 357 meteorological stations having the good quality and continuous daily records of air temperature from 1956 to 2013. These 357 meteorological stations are not evenly distributed and most of them are located in central and eastern China (Fig. 1).

China is located in the northern hemisphere, extreme hot days or heat waves are seen in summer (June, July, and August, JJA), while extreme cold days or cold waves commonly occur in winter (December, January and February, DJF) (Xu et al. 2011). In each calendar year, the annual highest daily maximum temperature (AMaxT) could be simply extracted from the daily maximum temperature dataset. However, annual lowest daily minimum temperature (AMinT) is extracted from the daily minimum temperature dataset from November to the next February. The summer mean daily maximum temperature (SMMaxT) and winter mean daily minimum (WMMinT) temperature are also computed as covariate in nonstationary extreme value distributions.

WPSHI data (monthly and annual) is provided by the U.S. National Centers for Environmental Prediction (NCEP). In each calendar year, we compute the summer averaged WPSHI as covariate in nonstationary GEV distributions of AMaxT. The winter averaged AOI data, which

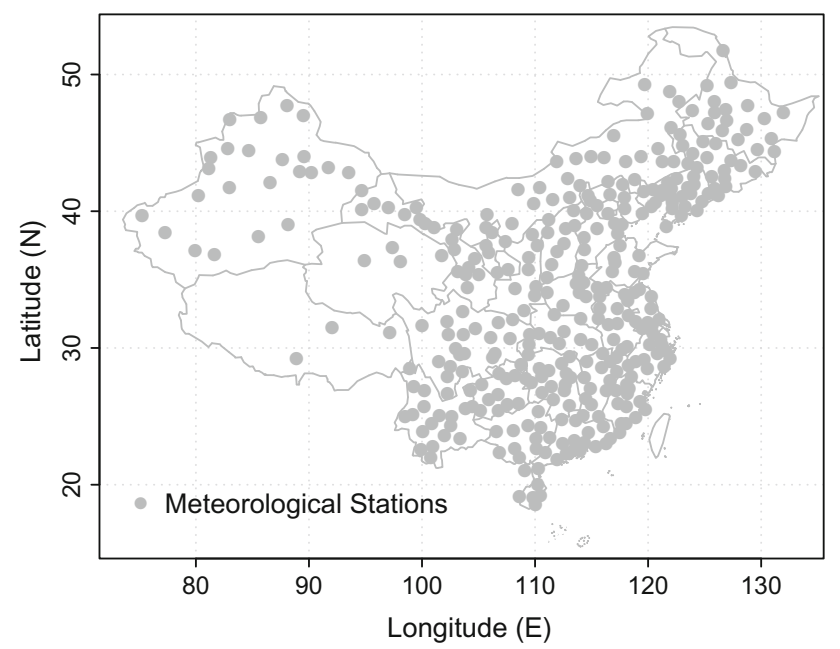

Fig. 1 Geographical distribution of the 357 meteorological stations in China is extracted from the Climate Prediction Center of the National Oceanic and Atmospheric Administration (NOAA-CPC), is also used as covariate in nonstationary GEV distributions of AMinT.

To understand the changing patterns of large scale atmospheric circulation, the reanalysis data of monthly mean geopotential height and wind fields at $850 \mathrm{hPa}$ are downloaded from the National Centers for Environmental Prediction/National Center for Atmospheric Research (NCEP/NCAR) and analyzed. The NCEP/NCAR Reanalysis 1 project uses a state-of-the-art analysis/forecast system to perform data assimilation based on past data from 1948 to the present. The spatial resolution of global dataset is $2.5^{\circ} \times 2.5^{\circ}$ (Kalnay et al. 1996).

\section{Methodology}

\subsection{Quantile regression}

Quantile regression, initiated by Koenker and Bassett (1978), offers an trend-detection approach for identifying changes over time of any percentile values of climate variables (Barbosa 2008; Donner et al. 2012). Moreover, quantile regression can also be used for detecting the relation between climate extremes and large-scale climate patterns (Tareghian and Rasmussen 2012; Fan and Xiong 2015; Tan and Shao 2017). It is proposed as an extension to the traditional linear regression, which approximates quantiles of the response variable (Koenker and Bassett 1978). The widely used linear quantile regression minimizes the functional

$\sum_{i=1}^{n} \rho_{\tau}\left(h_{i}-X_{i}^{T} \beta\right)$

where $\rho_{\tau}(\mu)=\tau \mu I_{(0, \infty)}(\mu)-(1-\tau) \mu I_{(-\infty, 0)}(\mu)$ is the check function; $I_{A}(\mu)$ is the indictor function that equals to 1 , if $\mu \in A ; n$ is the length of the observed time series $h$; $X_{i}=\left(X_{i 1}, \ldots, X_{i m}\right)^{T}$ ( $m$ is the number of covariates minus one), where $X_{i 1}=1$ for the intercept, $X_{i}$ includes a vector of time points as one element but can also contain external factors such as climate indices; $\beta$ denotes the parameter vector to be estimated and $\tau$ is the quantile level (Yu et al. 2003; Koenker 2005). Generally, the estimated quantile curves at multiple quantiles might cross leading to an invalid distribution for the response (Wu and Liu 2009; Bondell et al. 2010). In this study, Bondell et al.'s noncrossing quantile regression method is adopted (Bondell et al. 2010). The estimated coefficients are considered to be significantly different from zero at the $5 \%$ significance level only zero is outside of the $95 \%$ confidence interval, which is computed using a $(x, y)$-pair bootstrap method. 
Trends are first detected using the non-crossing quantile regression method at the three quantile levels $\tau=0.1,0.5$ and 0.9 , corresponding to 10,50 and $90 \%$ percentiles of AMaxT or AMinT, respectively. Quantile regression for the median $(\tau=0.5)$ provides measures of central tendency. Moreover, the difference of quantile trends at $\tau=$ 0.9 and $\tau=0.1$ represents the temporal evolution of "dispersion" of AMaxT (or AMinT). Positive value of quantile trend difference indicates an increasing amplitude of interannual variability of AMaxT (or AMinT), while negative value of quantile trend difference indicates a decreasing amplitude of interannual variability. Next, quantile regression is also used to detect the correlation between annual temperature extremes and the two large scale climate patterns: the WPSH and the AO. In each quantile regression model, AMaxT or AMinT is used as response variable, and the two normalized climate indices, WPSHI or AOI, are taken as predictor. Quantile slopes are also estimated at three quantile levels $\tau=0.1,0.5$ and 0.9 . Analogously, quantile slope at median $(\tau=0.5)$ represents the relationship between annual temperature extremes and climate indices, while the difference of quantile slopes at $\tau=0.9$ and $\tau=0.1$ represents the evolution of "dispersion" of AMaxT (or AMinT) with the increase of climate indices.

\subsection{Nonstationary GEV distribution}

GEV distribution has been commonly applied to the most extreme values within a period, typically annual maxima or minima. The cumulative probability distribution function of GEV distribution is expressed as (Coles 2001):

$F(x)=\exp \left\{-\left[1+\varepsilon\left(\frac{x-\mu}{\sigma}\right)\right]^{-1 / \varepsilon}\right\}, 1+\frac{\varepsilon(x-\mu)}{\sigma}>0$

where $\mu, \sigma>0$, and $\varepsilon$ are the location, scale, and shape parameters, respectively. Constant parameters correspond to stationary GEV distribution, while time-varying parameters correspond to nonstationary GEV distribution. The time-varying parameters in nonstationary GEV distribution could be modeled as the function of time or other climate indictors (Katz 2013):

$F_{y}(x)=\exp \left\{-\left[1+\varepsilon_{y}\left(\frac{x-\mu_{y}}{\sigma_{y}}\right)\right]^{-1 / \varepsilon_{y}}\right\}$

where $y$ is the year index. Commonly, the location parameter $\mu_{y}$ and/or the scale parameter $\sigma_{y}$ are assumed time-varying, while the shape parameter is assumed constant through time (Coles 2001; Katz 2013; Kharin et al. 2013; Cheng et al. 2014; Salas and Obeysekera 2014; Wi et al. 2016).
For AMaxT, three covariates (the year index, SMMaxT, and WPSHI) were used in the nonstationary GEV distributions. For AMinT, three covariates (the year index, WMMinT, and AOI) were used. It should be noted that the AMinT should be sign-changed before fitting to a nonstationary GEV distribution (Coles 2001). In all nonstationary GEV distributions, we assume that the location parameter is linearly dependent on one of the three covariates. Additionally, a log-linear trend in the scale parameter ensures that it remains positive (Kharin and Zwiers 2005). More complex dependence is not investigated as linear forms are deemed an adequate first-order approximation to any non-stationarity (Brown et al. 2008). The covariate, year index, during the observational period is scaled to range from 0 to 1 for numerical reasons. Other covariates in nonstationary GEV distributions are also standardized before fitting the annual temperature extremes for computational simplicity. All stationary and nonstationary GEV distributions are listed in Table 1. Maximum likelihood method is primarily used for parameter estimation in both stationary and nonstationary GEV distributions. There are a few of criteria available for stationary and nonstationary GEV model fitting evaluation, and the Bayesian information criterion (BIC) is recommended for nonstationary GEV model selection (Panagoulia et al. 2014; Kim et al. 2017). The model with the lowest BIC is considered as the

Table 1 Stationary and nonstationary GEV distribution models and the specification of the parameters

\begin{tabular}{ll}
\hline Model ID & Parameter forms* \\
\hline$M 0$ & $\mu_{y}=$ constant, $\sigma_{y}=$ constant \\
$M 1$ & $\mu_{y}=\alpha_{0}+\alpha_{1} y, \sigma_{y}=$ constant \\
$M 2$ & $\mu_{y}=$ constant, $\sigma_{y}=\exp \left(\beta_{0}+\beta_{1} y\right)$ \\
$M 3$ & $\mu_{y}=\alpha_{0}+\alpha_{1} y, \sigma_{y}=\exp \left(\beta_{0}+\beta_{1} y\right)$ \\
$M 4$ & $\mu_{y}=\alpha_{0}+\alpha_{1} A V E, \sigma_{y}=\operatorname{constant}$ \\
$M 5$ & $\mu_{y}=$ constant, $\sigma_{y}=\exp \left(\beta_{0}+\beta_{1} A V E\right)$ \\
$M 6$ & $\mu_{y}=\alpha_{0}+\alpha_{1} A V E, \sigma_{y}=\exp \left(\beta_{0}+\beta_{1} A V E\right)$ \\
$M 7$ & $\mu_{y}=\alpha_{0}+\alpha_{1} C L I, \sigma_{y}=\operatorname{constant}$ \\
$M 8$ & $\mu_{y}=$ constant, $\sigma_{y}=\exp \left(\beta_{0}+\beta_{1} C L I\right)$ \\
$M 9$ & $\mu_{y}=\alpha_{0}+\alpha_{1} C L I, \sigma_{y}=\exp \left(\beta_{0}+\beta_{1} C L I\right)$ \\
$M 10$ & $\mu_{y}=\alpha_{0}+\alpha_{1} y, \sigma_{y}=\exp \left(\beta_{0}+\beta_{1} A V E\right)$ \\
$M 11$ & $\mu_{y}=\alpha_{0}+\alpha_{1} A V E, \sigma_{y}=\exp \left(\beta_{0}+\beta_{1} y\right)$ \\
$M 12$ & $\mu_{y}=\alpha_{0}+\alpha_{1} y, \sigma_{y}=\exp \left(\beta_{0}+\beta_{1} C L I\right)$ \\
$M 13$ & $\mu_{y}=\alpha_{0}+\alpha_{1} C L I, \sigma_{y}=\exp \left(\beta_{0}+\beta_{1} y\right)$ \\
$M 14$ & $\mu_{y}=\alpha_{0}+\alpha_{1} A V E, \sigma_{y}=\exp \left(\beta_{0}+\beta_{1} C L I\right)$ \\
$M 15$ & $\mu_{y}=\alpha_{0}+\alpha_{1} C L I, \sigma_{y}=\exp \left(\beta_{0}+\beta_{1} A V E\right)$ \\
\hline
\end{tabular}

* The shape parameter $\varepsilon$ always keeps constant. $y$ is the year index. $A V E$ stands for mean daily maximum (or minimum) temperature in summer (or winter). CLI stands for climate index (WPSHI or AOI) 
best one. In this study, nonstationary extreme value modeling is implemented using the R package "extRemes".

The two approaches, quantile regression and nonstationary extreme value modeling, have their own advantages and disadvantages. In many respects, they are complementary. Quantile regression has the advantage of not requiring the assumption of a specific form of probability distribution such as the GEV, but has the disadvantage of being less parsimonious in requiring fitting each quantile separately. In GEV approach, all the quantiles can be fitted simultaneously. The results of both approaches could be directly comparable. Specifically, the estimate of parameter $\alpha_{1}$ (Table 1) in the best nonstationary GEV model should be positively correlated to the quantile slopes in the median as estimated by quantile regression. The estimate of parameter $\beta_{1}$ (Table 1) in the best nonstationary GEV model should be positively correlated to the difference of quantile slopes at $\tau=0.9$ and $\tau=0.1$. In this study, the above-mentioned positive correlation will be presented using linear regression.

\section{3 $T$-year return level}

A $T$-year return level is defined under stationarity as the threshold that is exceeded by an annual extreme in any given year with the probability $p=1 / T$, where $T$ is expressed in years (Kharin et al. 2007). Denoting a random variable $M_{y}$ as the annual maximum of climate extremes (AMaxT and AMinT in this study) for year $y$ and assuming $\left\{M_{y}\right\}(y=1,2, \ldots)$ are temporally independent, the cumulative probability distribution of $M_{y}$ is (Cooley 2013)

$F_{y}(x)=P\left(M_{y} \leq x\right)$

Under stationary condition, $\left\{M_{y}\right\}$ are identically distributed with a probability distribution function $F(x)$, where the year index $y$ has been discarded for notational simplicity. The relationship between a return period $(T)$ and the associated return level $\left(x_{T}\right)$ can be revealed by the following equation (Coles 2001):

$F\left(x_{T}\right)=P\left(M \leq x_{T}\right)=1-1 / T$

where $x_{T}$ is the $(1-1 / T)$-th quantile of the probability distribution of climate extreme in any year. That is, we have $P\left(M>x_{T}\right)=1 / T$. That means the exceedance probability over the return level $x_{T}$ is $1 / T$ for each year.

Under nonstationary condition, $\left\{M_{y}\right\}$ are no longer identically distributed, where the dependence of probability distributions $F_{y}(x)$ on the year index $y$ should be considered. In term of time series analysis, a return period has the following two interpretations under stationarity. First, a return period $T$ could be interpreted as the expected waiting time until an exceedance over a level $x_{T}$ occurs (Olsen et al. 1998; Cooley 2013). We define $Y$ as the waiting time (from $y=0$ ), then the expectation of waiting time $Y$ is computed as :

$E[Y]=1+\sum_{i=1}^{\infty} \prod_{y=1}^{i} F_{y}(x)$

Alternatively, the relationship between $T$ and $x_{T}$ could also be interpreted as: there is one exceedance incident over a given exceedance level $x_{T}$ within a period $T$ (Cooley 2013; Salas and Obeysekera 2014). We define a random variable $N$ as the number of exceedances over a given exceedance level $x$ occurring in $T$ years period beginning with the year $y=1$ and ending with year $y=T$, thus, the expectation of $N$ becomes (Parey et al. 2007, 2010)

$E[N]=\sum_{y=1}^{T}\left(1-F_{y}(x)\right)$

Cooley (2013) showed that the second interpretation was more preferable from the perspective of numerical computation. Replacing $E[N]$ with 1 , the $x_{T} \sim T$ relationship

could be formulated as:

$1=\sum_{y=1}^{T}\left(1-F_{y}\left(x_{T}\right)\right)$

With the fitted nonstationary GEV distributions $F_{y}(x)$ described in the previous section, the $T$-year return level of annual extremes of daily maximum/minimum air temperature could be computed by solving Eq. (8) numerically. In this study, particle swarm optimization (PSO) method is applied to solve Eq. (8), where the objective function is

$G\left(x_{T}\right)=\left|\sum_{y=1}^{T}\left(1-F_{y}\left(x_{T}\right)\right)-1\right|$

\section{Results}

\subsection{Trend and correlation identification}

Figure 2a shows the quantile trends of AMaxT at $\tau=0.5$ during 1956-2013 at the 357 meteorological stations in China. The numbers of stations with statistically significant positive, non-significant positive, significant negative, and non-significant negative quantile trends are $91,181,8$, and 77 , respectively. Negative quantile trends are distributed in a zone extending from northeastern to central China. The estimated changing rates ranges from $-0.58^{\circ} \mathrm{C} / \mathrm{dec}$ ade to $0.75^{\circ} \mathrm{C} /$ decade. The differences of quantile trends of AMaxT at $\tau=0.9$ and $\tau=0.1$ are shown in Fig. 2 b. 
(a) Quantile Trends Quantile $=0.5$

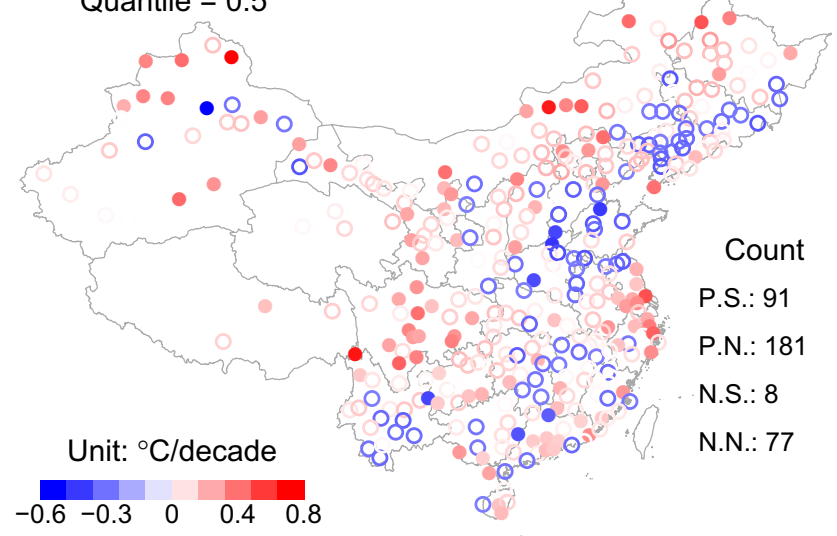

(c) AMaxT vs SMMaxT

$$
\text { Quantile }=0.5
$$

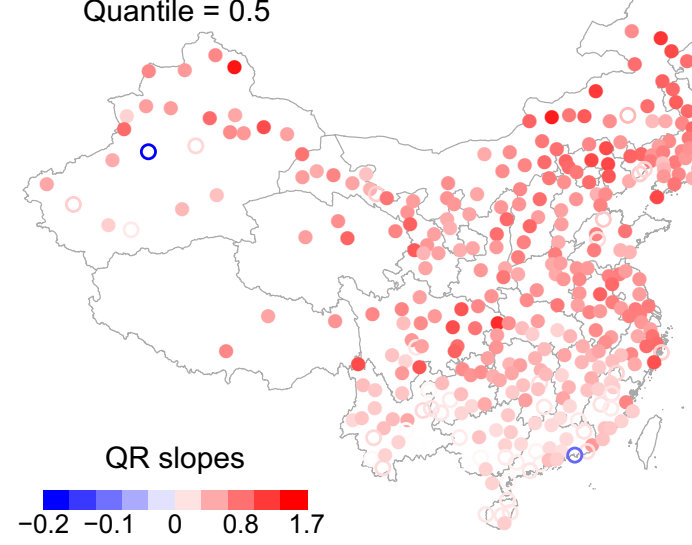

Count

P.S.: 311

P.N.: 44

N.S.: 0

N.N.: 2 (e) AMaxT vs WPSHI

$$
\text { Quantile }=0.5
$$

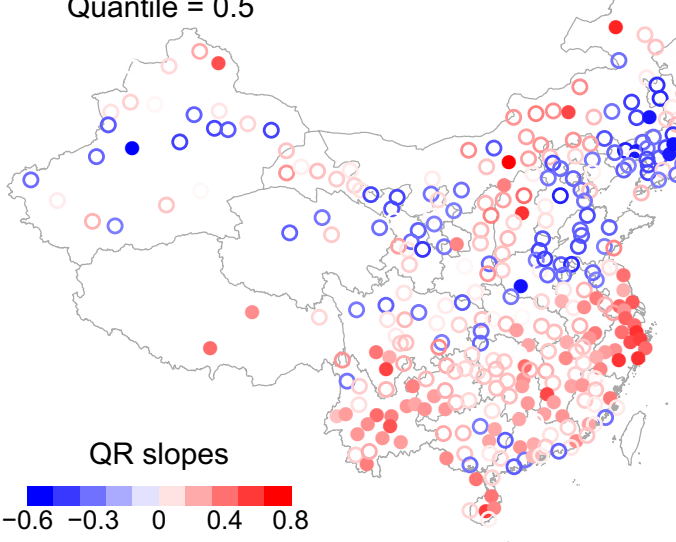

Fig. 2 Spatial patterns of quantile trends and slopes for AMaxT. (a, c, e) Quantile trends or slopes at $\tau=0.5 ;(\mathbf{b}, \mathbf{d}, \mathbf{f})$ difference of quantile trends or slopes at $\tau=0.9$ and $\tau=0.1$. Positive/negative values are shown as red/blue circles or up/down triangles, and the

Positive and negative differences are observed at 214 and 143 stations,respectively. Figure $2 \mathrm{c}$ presents the quantile slopes at $\tau=0.5$ of AMaxT with respect to SMMaxT. Out (b) Difference of QR trends

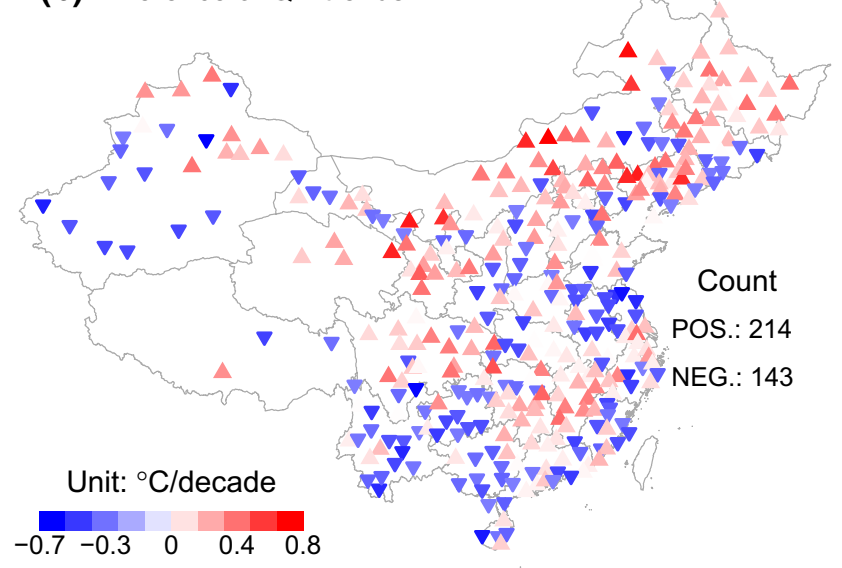

(d) AMaxT vs SMMaxT

\section{Difference of QR slopes}

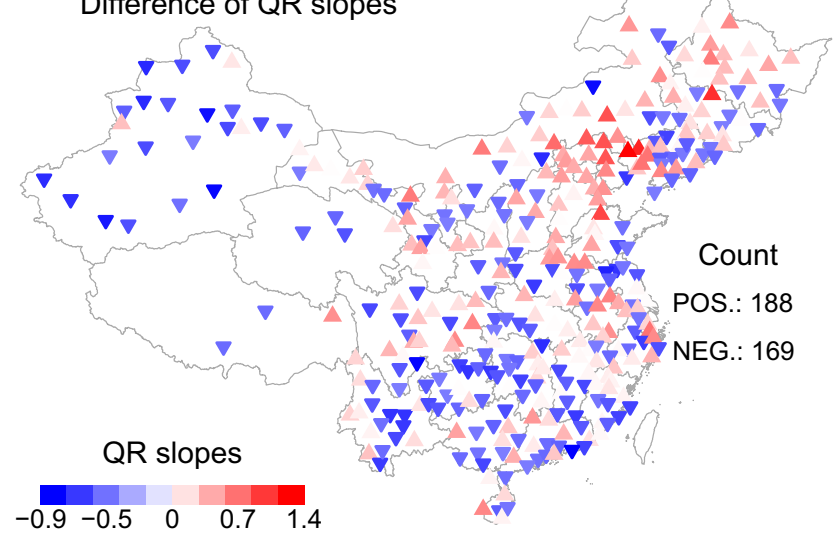

(f) AMaxT vs WPSHI

Difference of QR slopes

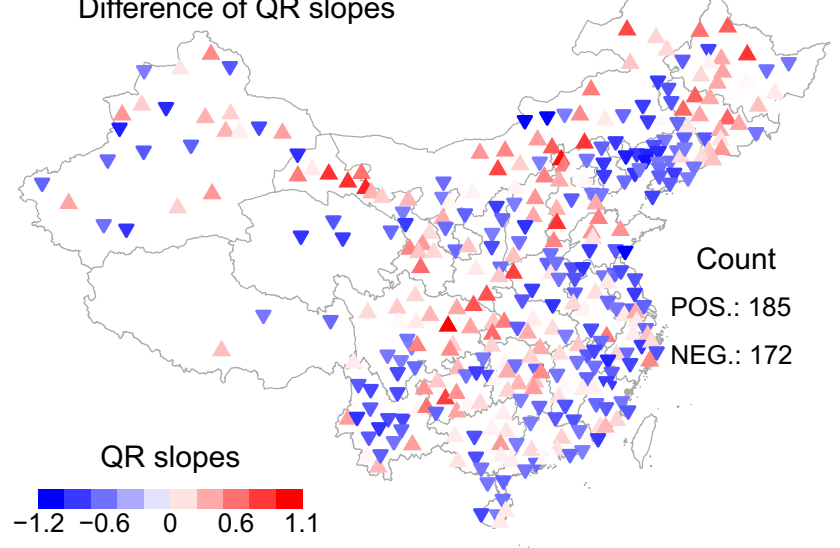

filled symbols represent statistically significant trends or slopes at the $5 \%$ level (P.S. positive and significant, P.N. positive and nonsignificant, N.S. negative and significant, $N . N$. negative and non-significant)

of all 357 stations, 355 (99.4\%) have a positive slope. Nonsignificant negative slopes (5\% significance level) are only detected at 2 stations. The differences of quantile slopes at 
$\tau=0.9$ and $\tau=0.1$ presented in Fig. $2 \mathrm{~d}$ show that the amplitude of interannual variability of AMaxT increases at 188 stations but decreases at 169 stations with the increase of SMMaxT. Results of relationship between AMaxT and the summer averaged WPSHI are shown in Fig. 2e. There are 247 stations showing positive quantile slopes and 79 of them are significant at 5\% level. These 79 stations are mainly distributed in southern China. Changes of amplitude of interannual variability of warm extremes with the increase of summer averaged WPSHI have also been detected (Fig. 2f).

Figure $3 \mathrm{a}$ shows the quantile trends of AMinT at $\tau=0.5$. There are 267 and 76 stations showing significant and non-significant positive trends, and quantile trends are higher in northern China than that in southern China. Negative quantile trends have detected at a few of stations, while only one negative trend is statistically significant (5\% significance level). The estimated changing rates ranges from $-0.39^{\circ} \mathrm{C} /$ decade to $1.96^{\circ} \mathrm{C} /$ decade. The differences of quantile trends of AMinT at $\tau=0.9$ and $\tau=0.1$ are shown in Fig. 3b. The changes of amplitude of interannual variability of AMinT are also verified by the positive (at 144 stations) and negative (at 213 stations) quantile trend differences. Figure $3 \mathrm{c}$ presents the quantile slopes at $\tau=0.5$ of AMinT with respect to WMMinT. At all stations, the quantile slopes are positive and statistically significant indicating the consistency between AMinT and WMMinT. The quantile differences are positive at 144 stations but negative at 213 stations (Fig. 3d). In Fig. 3e, quantile regression reveals the relationship between AMinT and the winter averaged AOI. We find that cold extremes in northwestern, northeastern, and eastern China are significantly affected by the AO (Fig. 3e). The differences of quantile slopes at $\tau=0.9$ and $\tau=0.1$ are positive and negative at 190 and 167 stations, respectively.

\subsection{Extreme value modeling}

The 16 stationary and nonstationary GEV distributions listed in Table 1 are first fitted to AMaxT at 357 stations. The potential covariates in nonstationary GEV distribution are year index, SMMaxT, and summer averaged WPSHI. At each station, the best model with the lowest BIC value has been selected from the 16 candidate models. The results of model selection are shown graphically in Fig. 4. Stationary GEV distribution model $M 0$ is chosen as the best model at 14 stations. Models M4, M6, M11, and M14 are chosen as the best models at $238,26,17$, and 16 stations, respectively. These 4 nonstationary GEV distribution models accounted for $83 \%$ of the 13 selected best models (Fig. 4). In these four GEV distribution models, the location parameter is always linearly dependent on the SMMaxT. Linear regression shows that the estimate of parameter $\alpha_{1}$ in models $M 4, M 6, M 11$, and $M 14$ is positively correlated with the quantile slopes shown in Fig. 2c at $\tau=0.5$ (Fig. 5a). Model $M 7$ has been chosen as the best models at 19 stations (Fig. 4). In model M7, the location parameter is linearly dependent on the summer averaged WPSHI. Figure 5a also shows that the result of nonstationary GEV modeling is consistent with that of quantile regression. In model $M 6, M 11$, and $M 14$, the scale parameter in dependent on SMMaxT, summer averaged WPSHI, and year index, respectively. The positive correlation between the estimate of parameter $\beta_{1}$ and the difference of quantile slopes at $\tau=0.9$ and $\tau=0.1$ verifies the consistency of quantile regression and nonstationary GEV modeling (Fig. 5b). In summary, we note that the results of nonstationary GEV modeling and quantile regression for annual warm extremes are consistent at most stations.

In the same way, the 16 stationary and nonstationary GEV distribution models are fitted to AMinT, where the potential covariates are year index, WMinT, and the winter averaged AOI. Figure 6 summarizes the results of model selection graphically. Analogously, models $M 4, M 6, M 11$, and $M 14$ are more selected as the best model, and these 4 models accounted for $93 \%$ of the 8 selected models. The estimated values of $\alpha_{1}$ in these four models are positively correlated to the quantile slopes at $\tau=0.5$ (Fig. 7a). Model $M 9$ and $M 12$ have been chosen as the best models at 12 and 9 stations, respectively (Fig. 6). In these two models, the location parameter is linearly dependent on winter averaged AOI or year index. The estimated $\alpha_{1}$ in these two models is also positively correlated to linear quantile slopes in the median (Fig. 7a). The positive correlations between $\beta_{1}$ in these nonstationary GEV models and the difference of quantile slopes at $\tau=0.9$ and $\tau=0.1$ are shown in Fig. $7 \mathrm{~b}$. However, the corresponding $R^{2}$ values are low. In summary, for annual cold extremes, the estimated location parameters in the nonstationary GEV modes are consistent with the linear quantile slopes in the median, while the estimated scale parameters are not highly consistent with the difference of linear quantile slopes at $\tau=0.9$ and $\tau=0.1$.

\subsection{Change of 20-year return level}

The best GEV distribution model has been identified for AMaxT and AMinT at all 357 stations. Then, the 20-year return levels of annual warm/cold temperature extremes in 1961-1980 and 1991-2010 are calculated based on Eqs. (5) and (8) for stationary and nonstationary GEV distribution models, respectively. Figure 6 shows the 20year return levels of AMaxT in 1961-1980 and 1991-2010 as well as the differences between them. The estimated 20- 
(a) Quantile Trends

Quantile $=0.5$

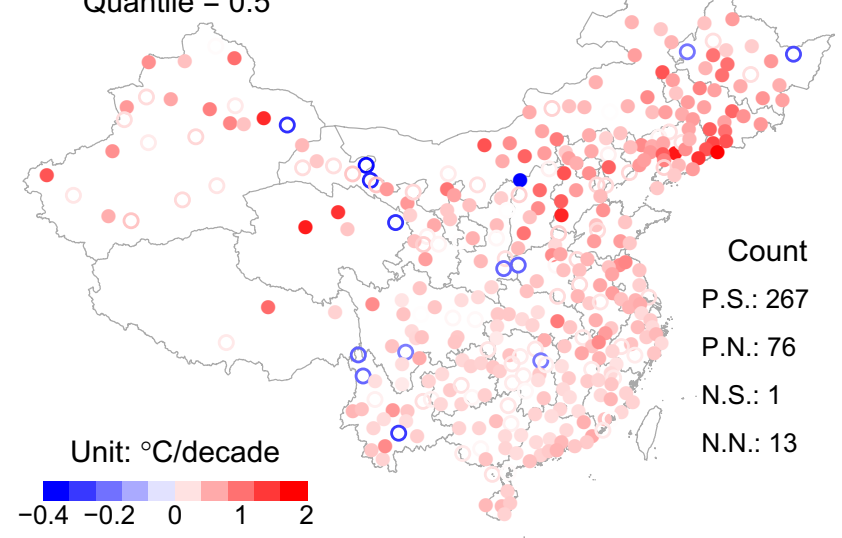

(c) AMinT vs WMMinT

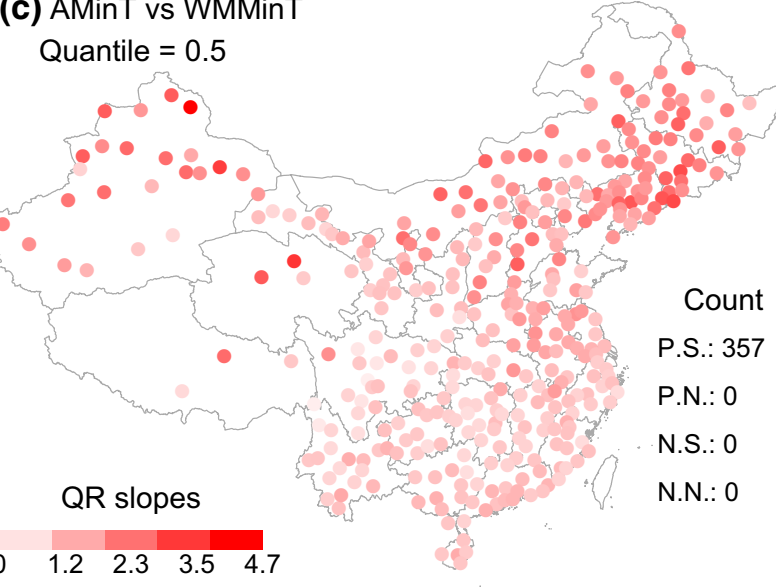

(e) AMinT vs AOI

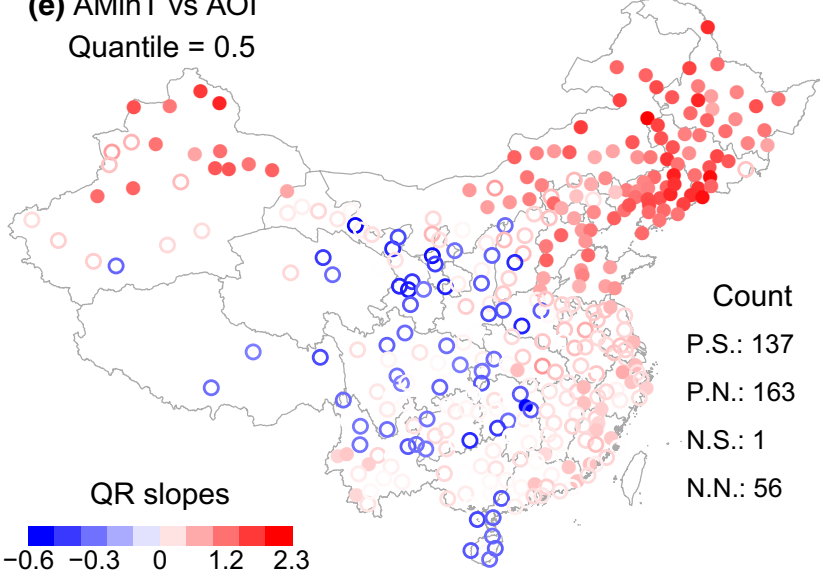

Fig. 3 Spatial patterns of quantile trends and slopes for AMinT. (a, c, e) Quantile trends or slopes at $\tau=0.5 ;(\mathbf{b}, \mathbf{d}, \mathbf{f})$ difference of quantile trends or slopes at $\tau=0.9$ and $\tau=0.1$. Positive/negative values are shown as red/blue circles or up/down triangles, and the filled symbols

year return level in 1961-1980 ranges from 21.44 to $47.44^{\circ} \mathrm{C}$ at the 357 stations (Fig. 8a). In 1991-2010, the range of 20-year return levels changed into 23.37 to (b) Difference of QR trends

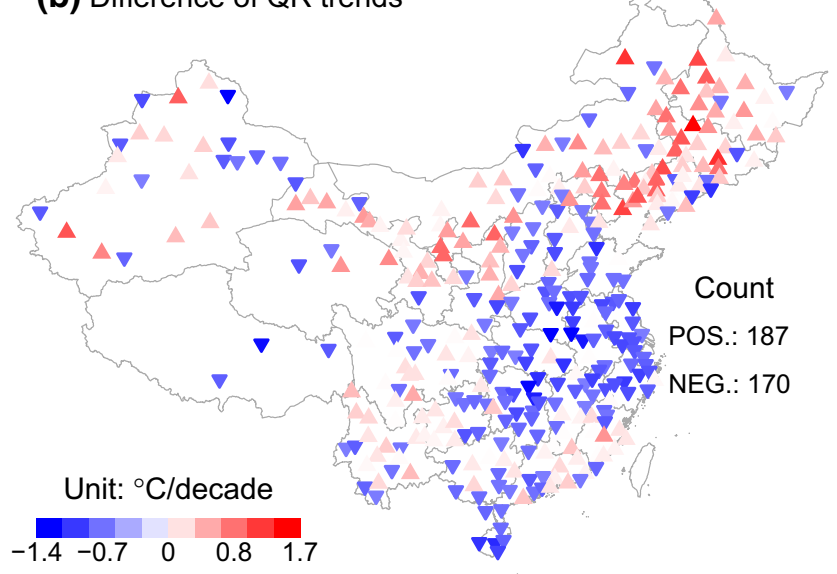

(d) AMinT vs WMMinT

\section{Difference of QR slopes}

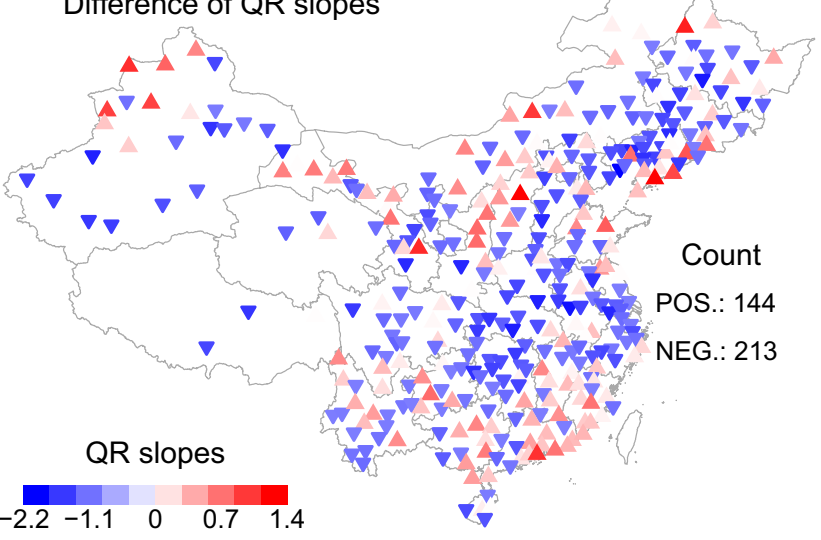

(f) AMinT vs AOI

Difference of QR slopes

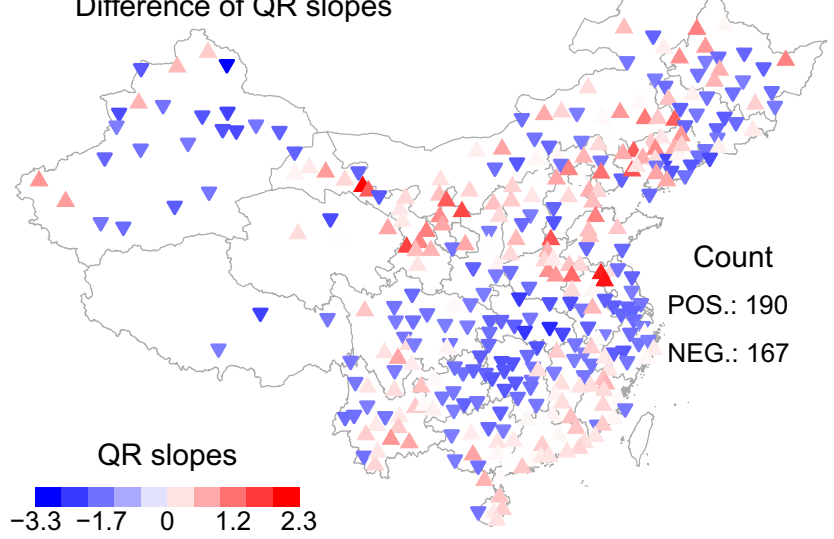

represent statistically significant trends or slopes at the 5\% level (P.S. positive and significant, P.N. positive and nonsignificant, N.S. negative and significant, $N . N$. negative and non-significant)

$48.01^{\circ} \mathrm{C}$ (Fig. 8b). As stationary GEV distribution model has also been selected as the best model at 14 stations (Fig. 4), the 20-year return values of AMaxT are the same 


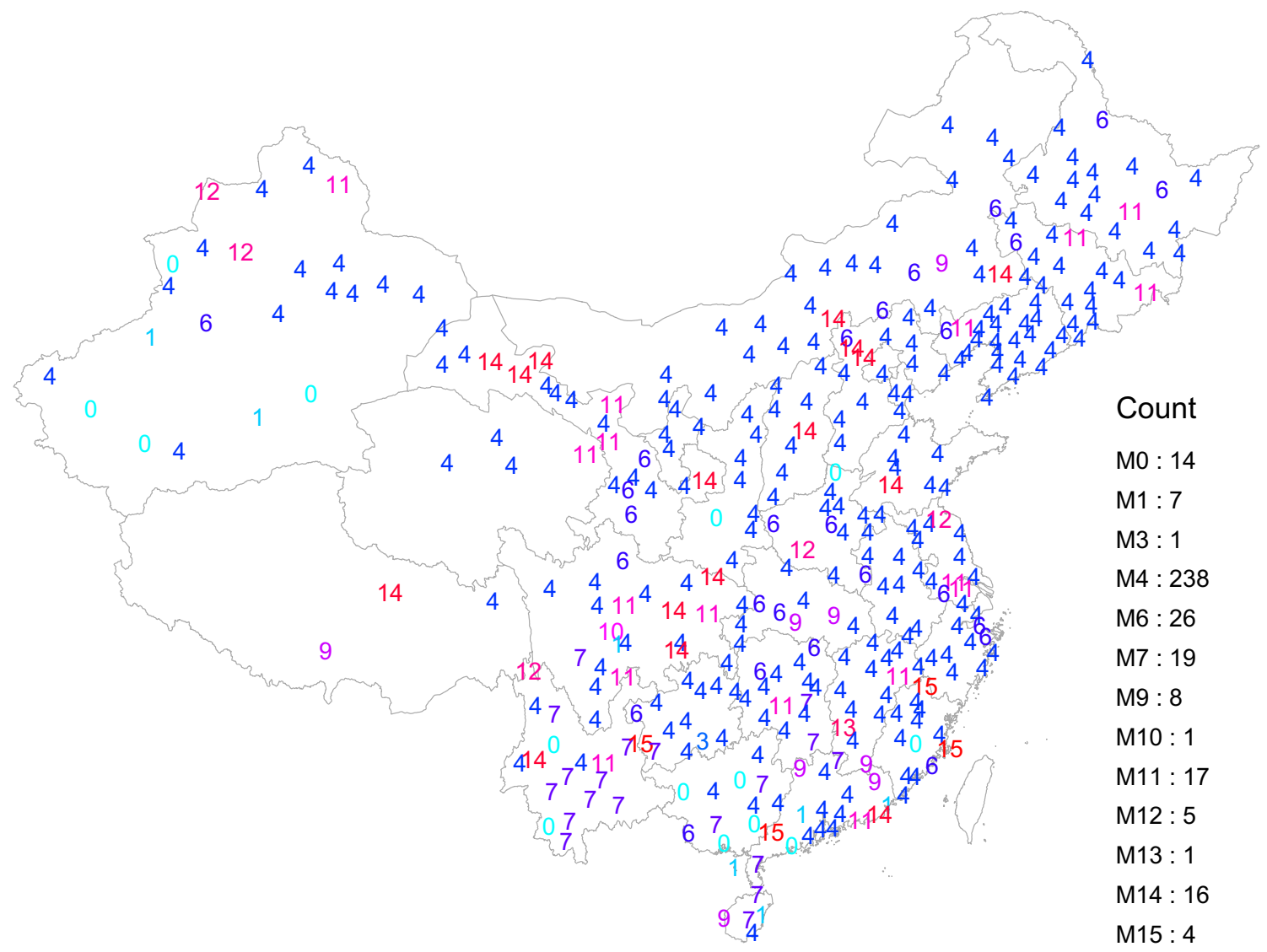

Fig. 4 Results of model selection for extreme value modeling of AMaxT

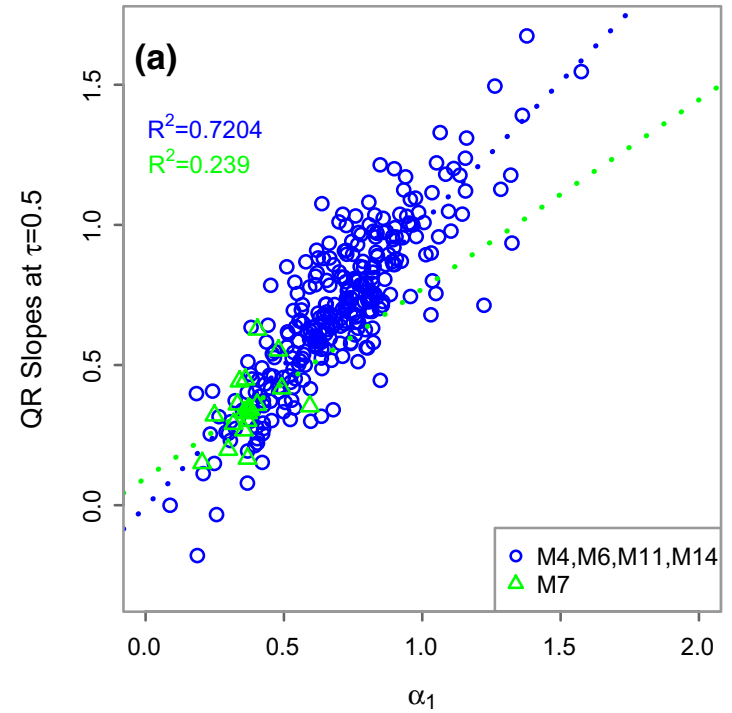

Fig. 5 a Results of linear regression of QR slopes in the median with respect to the estimated parameter $\alpha_{1}$ in nonstationary GEV model of annual warm extremes (AMaxT). b Results of linear regression of the

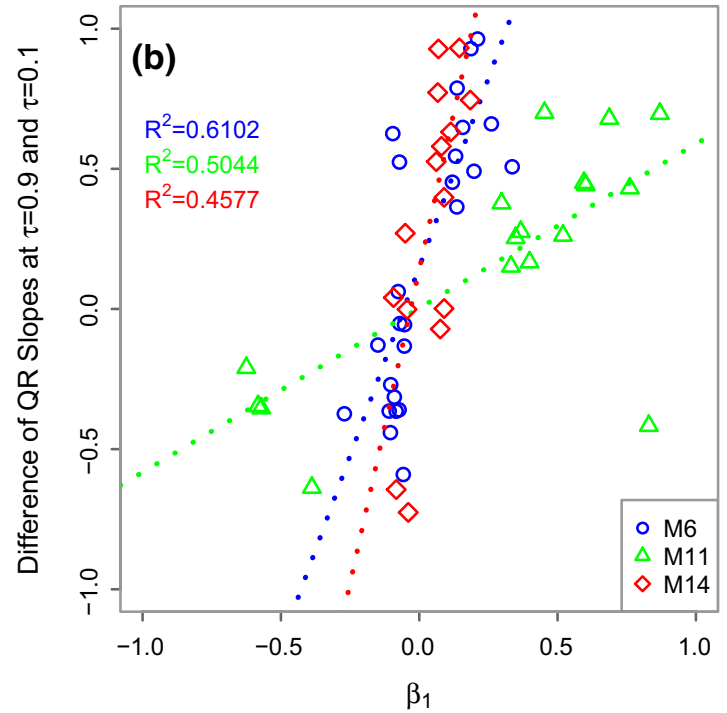

difference of QR slopes at $\tau=0.9$ and $\tau=0.1$ with respect to the estimated parameter $\beta_{1}$ in nonstationary GEV model of annual warm extremes (AMaxT) 


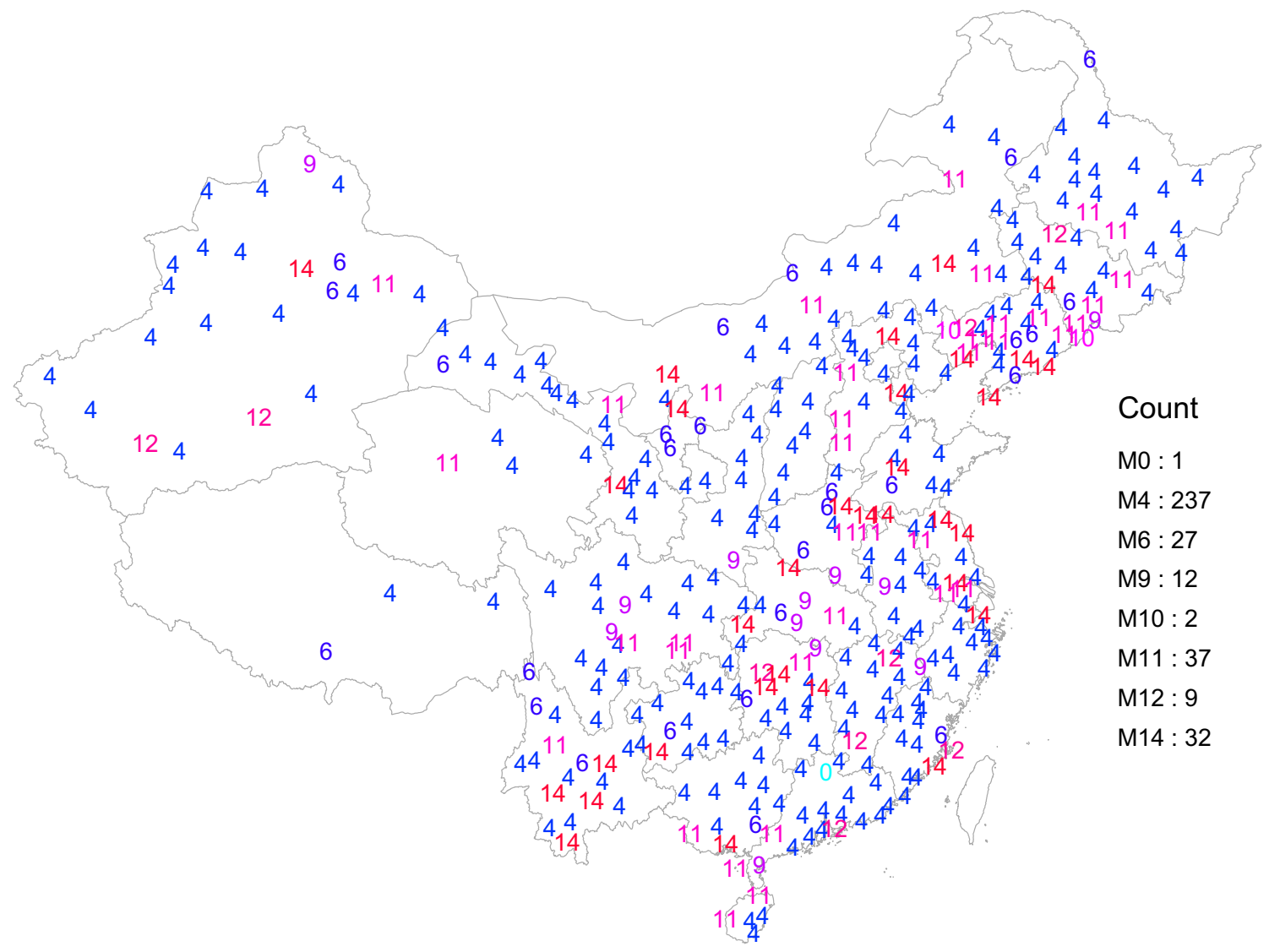

Fig. 6 Results of model selection for extreme value modeling of AMinT

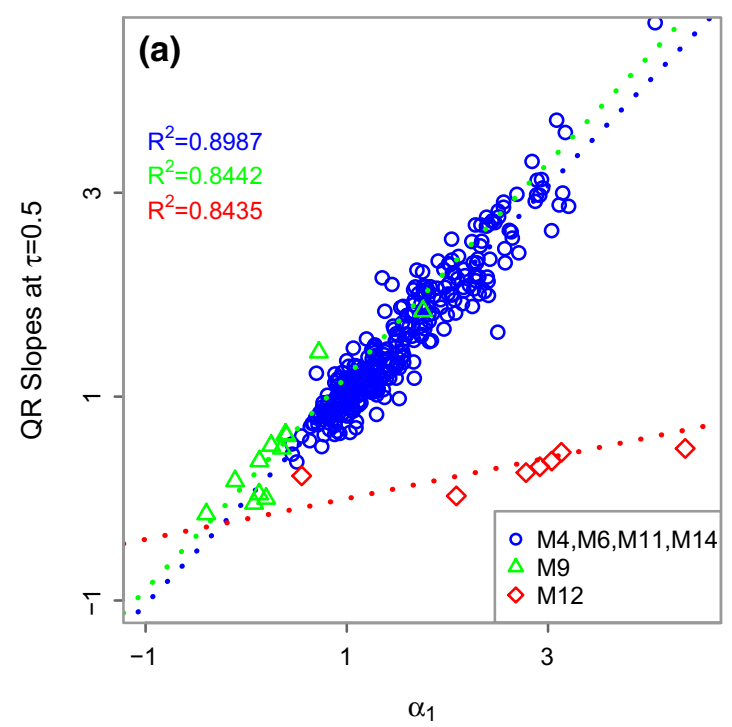

Fig. 7 a Results of linear regression of QR slopes in the median with respect to the estimated parameter $\alpha_{1}$ in nonstationary GEV model of annual cold extremes (AMinT). b Results of linear regression of the



difference of QR slopes at $\tau=0.9$ and $\tau=0.1$ with respect to the estimated parameter $\beta_{1}$ in nonstationary GEV model of annual cold extremes (AMinT) 
(a) 20-yr return level in 1961 1980

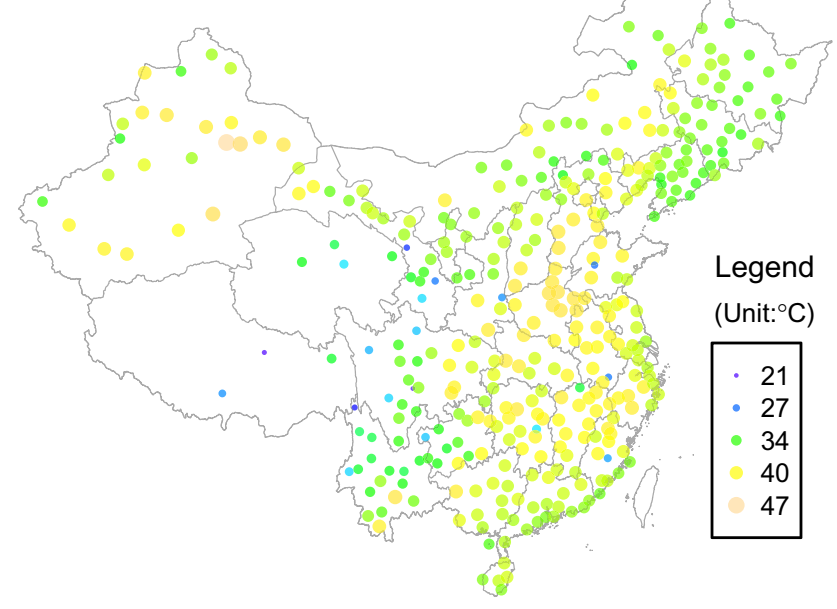

(b) 20-yr return level in 1991 2010

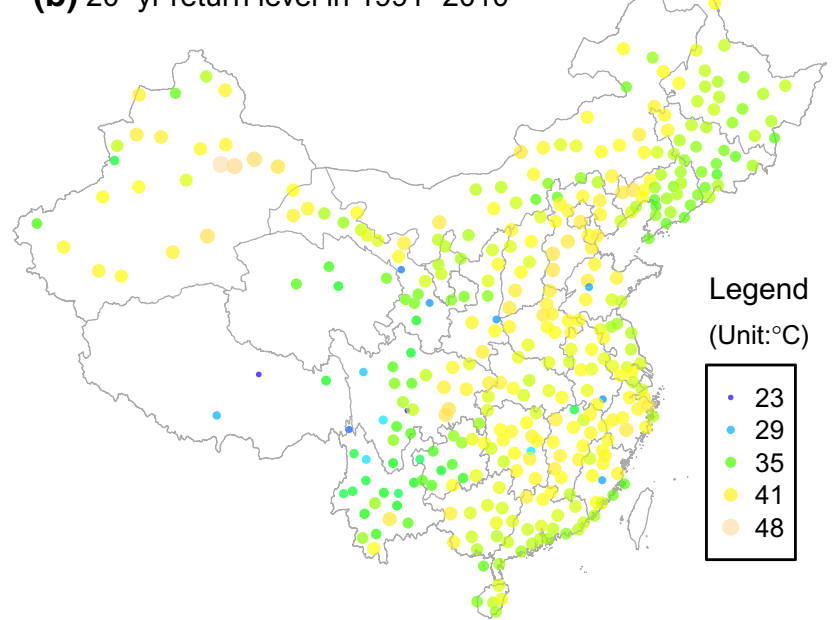

(c) Change of 20-yr return level

1991 2010 vs 1961 1980

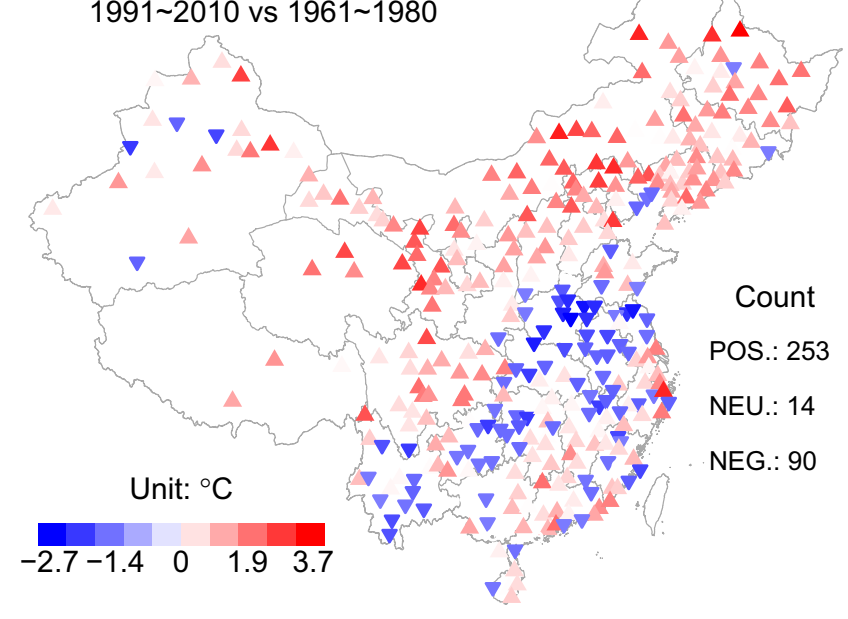

Fig. 8 a-b Spatial patterns of the estimated 20-year return levels of AMaxT in 1961-1980 and 1991-2010. c The difference of 20-year return levels between that in $\mathbf{b}$ and $\mathbf{a}$. Positive (negative) values are shown as up and red (down and blue) triangles, respectively

in 1961-1980 and 1991-2010 (Fig. 8c). At other stations, the 20-year return levels either increased or decreased, and the numbers of stations were 253 and 90 , respectively. We also find that the stations with decreased 20 -year return levels of daily maximum temperature extremes are mainly located in central and southwestern China. This result is partly consistent with the quantile trends at $\tau=0.5$ presented in Fig. 2a. In parallel, the 20-year return levels of AMinT in 1961-1980 and 1991-2010 as well as the differences are shown in Fig. 9. The estimated 20-year return level of AMinT in 1961-1980 ranges from -44.89 to $6.099{ }^{\circ} \mathrm{C}$ at the 357 stations (Fig. 9a). In 1991-2010, the range of 20-year return levels changed into -44.145 to $8.596{ }^{\circ} \mathrm{C}$ (Fig. 9b). The differences of 20 -year return level in 1961-1980 and 1991-2010 shows that the numbers of stations with increased, no change, and decreased 20-year return levels are 290, 1, and 66, respectively (Fig. 9c).

\section{Discussion}

\subsection{Change of temperature extremes and causes}

Quantile trends provide a more complete description of climate change, where not only temperature variability in the mean but also in extreme values can be investigated (Barbosa 2008; Donner et al. 2012). Moreover, the distributional changes of climate indices could also be detected using quantile regression (Shiau and Huang 2015; Tan and Shao 2017). In this study, quantile regression has revealed 
(a) 20-yr return level in 1961 1980

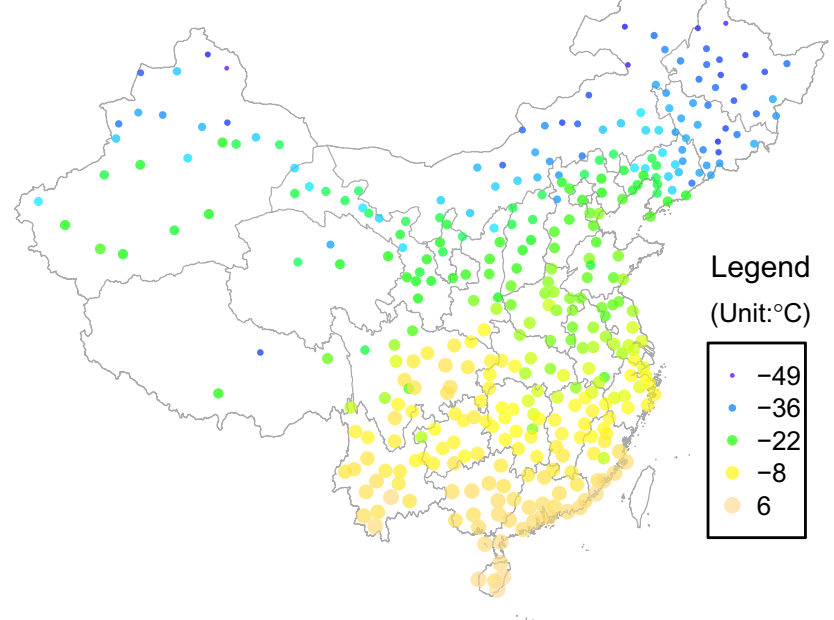

(b) 20-yr return level in 1991 2010

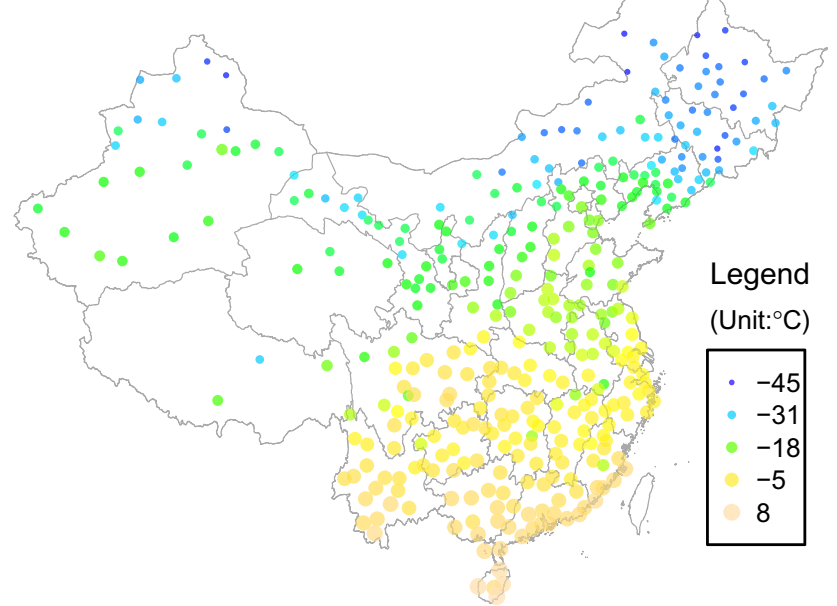

(c) Change of 20-yr return level

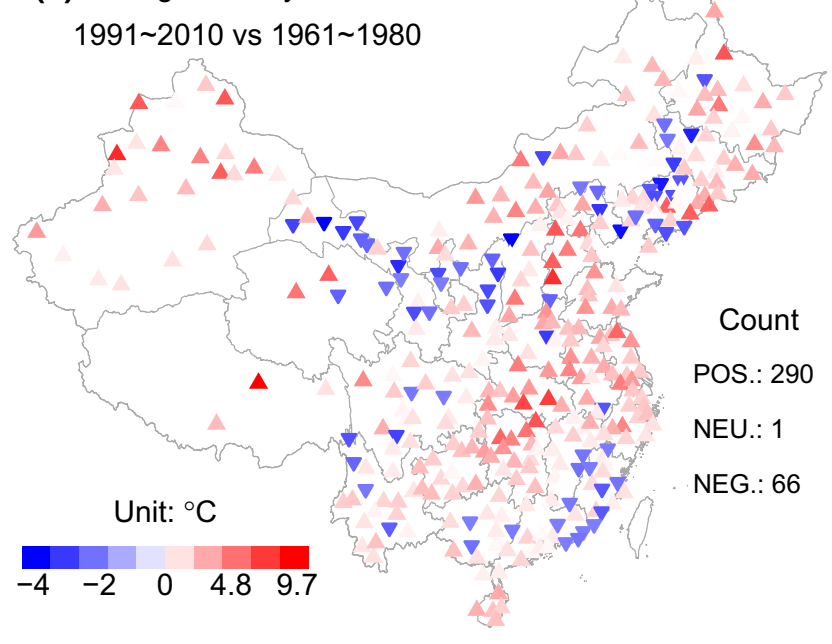

Fig. 9 a-b Spatial patterns of the estimated 20-year return levels of AMinT in 1961-1980 and 1991-2010. c The difference of 20-year return levels between that in $\mathbf{b}$ and $\mathbf{a}$. Positive (negative) values are shown as up and red (down and blue) triangles, respectively

the changes of temperature extremes and their correlations to large scale climate patterns. Overall the quantile trends of temperature extremes are consistent with the statistically significant warming trends detected in previous publications (Wang and Gong 2000; Zhai and Pan 2003; You et al. 2011; Zhou and Ren 2011). Cold extremes warmed faster than warm extremes during 1956-2013 (Fig. 2a and 3a), and this finding was consistent with the general pattern of global warming (IPCC 2007; Robeson et al. 2014). Decreasing trends were also detected in warm extremes at a few of stations (Fig. 2a). This result should not be surprising because a cooling trend was reported in earlier studies either (Ding et al. 2007). We also found that the warm (cold) temperature extremes were highly correlated with the mean daily maximum (minimum) temperature in summer (winter) reflecting the consistent warming (Fig. 2c and 3c). These high correlations verified the importance of SMMaxT or WMMinT as covariate in nonstationary extreme modeling.

To investigate the role of large scale atmospheric circulation change in climate change, atmospheric circulation composite analysis was usually conducted (You et al. 2011), where composite circulation maps showing the differences of wind fields and geopotential height between two periods were consequently created to represent the change in circulation. Figure 10 shows the mean difference of wind fields and geopotential height at $850 \mathrm{hPa}$ in summer and winter between 1991-2010 and 1961-1980, 

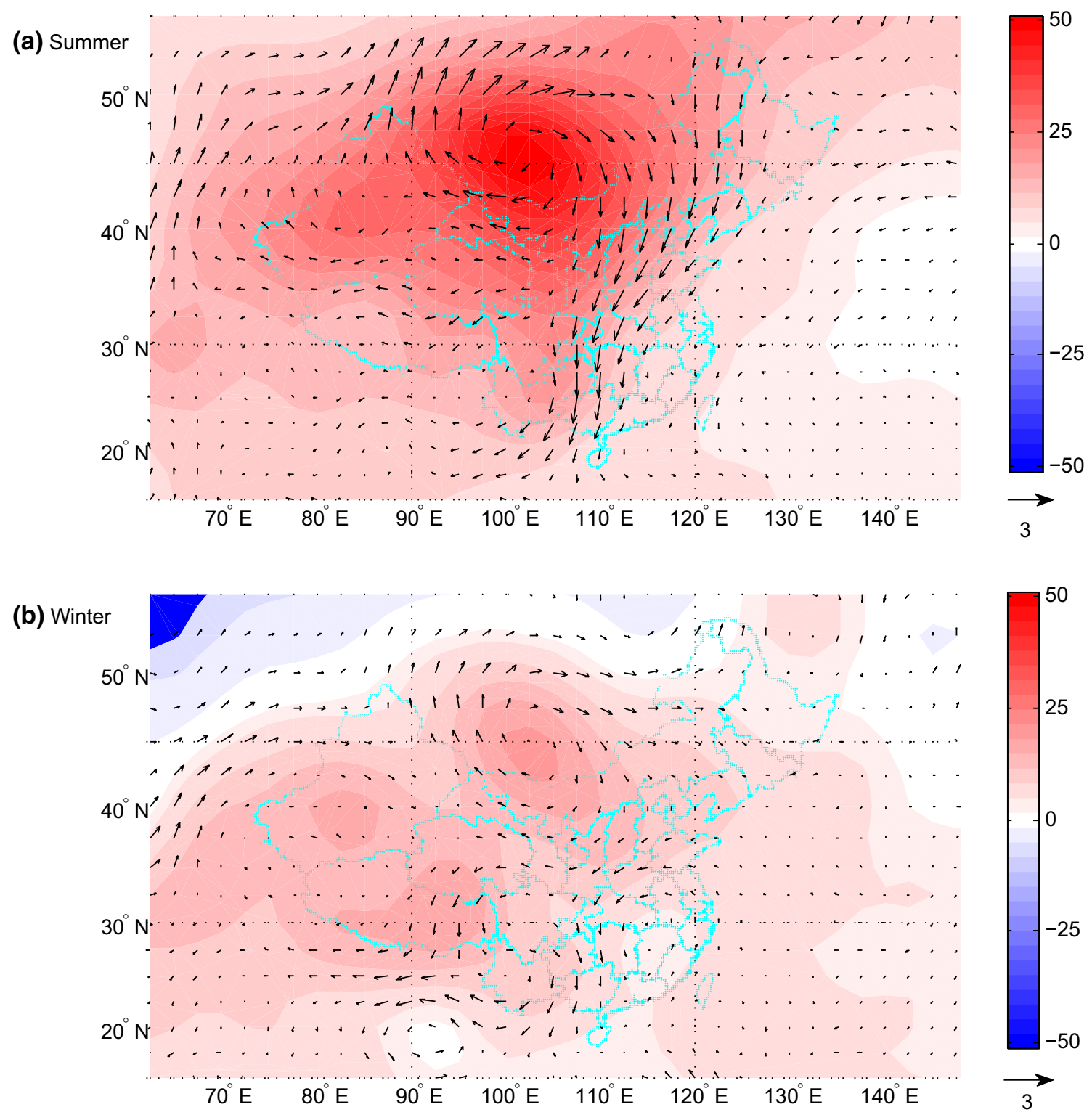

Fig. 10 Difference of wind speed and geopotential height at $850 \mathrm{hPa}$ in summer (a) and winter (b) between 1991-2010 and 1961-1980

respectively. As shown in Fig. 10a, the largest differences of geopotential height (approximately $50 \mathrm{gpm}$ ) occurred near $45^{\circ} \mathrm{N}$ and $100^{\circ} \mathrm{E}$ at $850 \mathrm{hPa}$ in summer (Fig. 10a), and enhanced anticyclonic circulation developed over the Eurasian continent and centered on Mongolia. The increased geopotential height over Mongolia was consistent with the positive trends of warm extremes in northern China (Fig. 2a and 8c). The northeasterly wind in northern and eastern China has strengthened, and in turn weakens the northern and eastern extent of the westerly jet stream and any southwesterly flow from the ocean. This may explain the decreasing trend of warm extremes in summer in northeastern and central China. In winter, two enhanced anticyclonic circulations located at northern and eastern China have developed. This would explain why the cold temperature extremes have consistently decreased in northern China, which is consistent with rapid warming in the region in winter (Fig. 3a). The changes in wind fields and geopotential height at $500 \mathrm{hPa}$ are generally similar to those at $850 \mathrm{hPa}$ height (not shown as figures). Besides circulation change, many factors, such as solar radiation, cloud coverage, sunshine hours, aerosols, urbanization also contributed to the changes in temperature extremes (Jones et al. 2008; Zhang et al. 2011). Actually, it is difficult to decide exactly what could be the influencing factors of changes in temperature extremes. In this study, we have not 
assessed the exact reasons for the changes in annual temperature extremes but plan to do so in subsequent study.

\subsection{Covariate selection}

In nonstationary extreme value modeling, determining the proper covariates and parameter forms is the primary work. Generally, we can construct plenty of candidate extreme value models by introducing extra covariates, i.e. the mean maximum or minimum temperature and climate indices. The WPSH is a large scale anticyclonic circulation located over the subtropical Pacific throughout the year and usually peaks in summer (Huang et al. 2015). It is also identified as one of the dominant components in the East Asian summer monsoon (EASM) system and has large influences on the East Asian summer climate. Therefore, the summer averaged WPSHI was chosen as the covariate of the nonstationary GEV distribution models of AMaxT. The AO, currently known as Northern Annular Mode, strongly influences surface air temperatures over the Eurasian continent (Thompson and Wallace 1998; Hurrell and Deser 2010). Specifically, AO could explain more than $50 \%$ of winter temperature extreme change in China (You et al. 2013). In this study, we found that AMinT was positively correlated with AOI at $84 \%$ stations and the positive correlations were significant (5\% level) at 137 stations. In this study, AOI has been chosen as the covariate of extreme value modeling of AMinT. Both quantile regression and model selection for nonstationary GEV showed that the roles of AOI and WPSHI were not as important as that of SMMaxT and WMMinT in nonstationary extreme value modeling. But that does not imply the roles of climate indices were not important in climate extreme changes. The relationships between climate extremes and climate indictors needed to be further examined but out of the scope of this study.

Besides the WPSH and the AO, some other large scale climate patterns such as El Niño-Southern Oscillation (ENSO) representing the variability of climate system could also affect temperature extremes in China. The mature phase of ENSO often peaks in boreal winter, persists into spring, and decays in the following summer $(\mathrm{Wu}$ et al. 2003). On the one hand, ENSO was found to be correlated with the winter temperature extremes only along the southeast coast of China (Chen et al. 2013). As the influence of ENSO on winter temperature extremes was not comparable to that of AO, ENSO index was not chosen as covariate in the nonstationary GEV distribution of AMinT. On the other hand, WPSH is remotely affected by ENSO (Huang et al. 2015); therefore, ENSO index was not chosen as covariate in the nonstationary GEV distribution of AMaxT.

\subsection{Return level of temperature extremes}

In stationary climate, the return level of annual climate extremes is thought to be constant in each year, and there exists a simple one-to-one relationship between a return period and a return level of climate extremes (Olsen et al. 1998; Cooley 2013). However, the concepts of return period (or return level) needed to be carefully reformulated and extended under nonstationary condition due to the time-varying essence of climate extremes (Katz 2010). Wigley (1988) used the definition of the return period as expected waiting time, and illustrated how non-stationarity affected the risk of extremes using some simple probability arguments. Olsen et al. (1998) extended the concept of return period to nonstationary condition, and proposed to use the return period that was defined as the expected waiting time until an exceedance as the measure of risk. Parey et al. $(2007,2010)$ extended the alternative interpretation of return period (expected number of extreme events in a given return period) under nonstationary conditions. Cooley (2013) reviewed these two return period definitions suggested by Olsen et al. (1998) and Parey et al. (2007, 2010), and proposed to communicate risk using return period in nonstationary climate. From the perspective of engineering design, Salas and Obeysekera (2014) illustrated the estimation of return period and examined the failure risk of hydrological structures in nonstationary climate. Rootén and Katz (2013) proposed a risk-based engineering design concept, Design Life Level, by keeping the failure risk at a low constant level during the design life period. As in Kharin et al. (2013), we computed the difference of $T$-year return levels in different periods to assess the changes of temperature extremes. In this study, we applied Parey et al.'s method $(2007,2010)$ to compute the $T$-year return level of temperature extremes under nonstationary conditions. The $T$-year return level estimated using Parey et al.'s method is determined by all $F_{y}(x)$ within the $T$-year period but extrapolation is not needed.

The changes of 20-year return levels of AMaxT were roughly consistent with the quantile trends. For cold temperature extremes, the number of stations with decreasing trends in 20-year return values was 66 , which was much larger than the number of stations with negative quantile trends. In this study, both the location parameter and the scale parameter in nonstationary GEV distribution were assumed to be time-varying. The changes of 20-year return levels of cold annual temperatures reflected not only the mean but also the dispersion of samples of AMinT. Additionally, the quantile trends were linear, while the scale parameter was assumed to be log-linear in nonstationary extreme value modeling. Therefore, the changes of of 20-year return levels of cold temperatures were not 
exactly the same as the estimated quantile trends. In addition, the extreme value model applied in this study was GEV distribution. Although more straightforward to apply, extensive extreme data is not included in GEV distribution model. Alternatively, a peaks-over-threshold (POT) model was recommended to describe all exceedances above a high threshold (Jahanbaksh Asl et al. 2011; Wi et al. 2016). Brown et al. (2008) applied the nonstationary peaks-over-threshold (POT) model to discern the changes in extreme temperatures by detecting the trends in the estimates of model parameters. For the nonstationary POT based model, the scale and shape parameters were also assumed to be time-varying generating time-varying $T$-year return levels. In applying nonstationary POT based model, there is additional important step, threshold selection, which should be carefully considered in nonstationary extreme value modeling of climate extremes.

\section{Conclusion}

In this paper, quantile regression was used to identify the trends of annual warm and cold temperature extremes and their correlations to two large climate patterns, the WPSH and the AO, at 357 stations in China. Significant warming trends have been detected in both warm and cold extremes during the period 1956-2013, and cold extremes warmed faster than warm extremes. In addition, quantile regression also detected the distributional changes (dispersion) of warm and cold temperature extremes. Analysis of largescale atmospheric circulation changes indicated that a strengthening anticyclonic circulation and increasing geopotential height in recent decades may have contributed to the changes in temperature extremes in China. The warm (cold) temperature extremes were highly correlated with the mean maximum (minimum) temperature in summer (winter), respectively. The influence of WPSH on warm extremes is significant in southern China, while the $\mathrm{AO}$ not only affects the cold extremes in northern and eastern China. The year index and the two climate indices, WPSHI and AOI, were chosen as covariates in nonstationary GEV distributions of annual extremes of daily maximum or minimum temperature, respectively. With the best fitting GEV model, the 20-year return levels of annual warm or cold extremes in the period 1961-1980 and 1991-2010 are computed and compared to to assess the changes of temperature extremes. It was concluded that the changes of 20-year return levels of AMaxT and AMinT were jointly determined by trend and distributional changes of annual temperature extremes.

Acknowledgements We sincerely acknowledge the editor and two anonymous reviewers whose kind and valuable comments greatly improved the quality of this manuscript. This work was partly supported by the Youth Innovation Promotion Association of CAS (2016195), CAS Knowledge Innovation Project (KZCX2-EWQN209), and National Natural Science Foundation of China (31570423). The authors also appreciated Dr. Reich for sharing the R-function "NoCrossQuant.R" to implement the non-crossing quantile regression.

\section{References}

Aguilar E, Peterson TC, Ramíez Obando P et al (2005) Changes in precipitation and temperature extremes in Central America and northern South America, 1961-2003. J Geophys Res 110:D23107

Alexander LV, Zhang X, Peterson TC, Caesar J, Gleason B, Klein Tank AMG, Haylock M, Collins D, Trewin B, Rahimzadeh F, Tagipour A, Rupa Kumar K, Revadekar J, Griffiths G, Vincent L, Stephenson DB, Burn J, Aguilar E, Brunet M, Taylor M, New M, Zhai P, Rusticucci M, Vazquez-Aguirre JL (2006) Global observed changes in daily climate extremes of temperature and precipitation. J Geophys Res 111:D05109

Barbosa SM (2008) Quantile trends in Baltic sea level. Geophys Res Lett 35(22):L22704

Barnston A, Livezey R (1987) Classification seasonality and persistence of low-frequency atmospheric circulation patterns. Mon Weather Rev 115:1083-1126

Bondell HD, Reich BJ, Wang H (2010) Noncrossing quantile regression curve estimation. Biometrika 97(4):825-838

Brown SJ, Caesar J, Ferro CAT (2008) Global changes in extreme daily temperature since 1950. J Geophys Res 113:D05115

Chen S, Chen W, Wei K (2013) Recent trends in winter temperature extremes in eastern China and their relationship with the Arctic Oscillation and ENSO. Adv Atmos Sci 30(6):1712-1724

Cheng L, AghaKouchak A, Gilleland E, Katz RW (2014) Nonstationary extreme value analysis in a changing climate. Clim Change 127:353-369

Christoph S, Gerd J (2004) Hot news from summer 2003. Nature 432:559-560

Coles S (2001) An introduction to statistical modeling of extreme values. Springer, Berlin

Cooley D (2013) Return periods and return levels under climate change. In: Easterling D, Hsu K, Schubert S, Sorooshian S, AghaKouchak A (eds) Extremes in a changing climate. Springer, Berlin, pp 97-114

Ding Y, Ren G, Zhao Z, Xu Y, Luo Y, Li Q, Zhang J (2007) Detection, causes and projection of climate change over China: an overview of recent progress. Adv Atmos Sci 24(6):954-971

Donner RV, Ehrcke R, Barbosa SM, Wagner J, Donges JF, Kurths J (2012) Spatial patterns of linear and nonparametric long-term trends in Baltic sea-level variability. Nonlinear Proc Geoph 19(1):95-111

Easterling DR, Meehl GA, Parmesan C, Mearns LO (2000) Climate extremes: observations, modeling, and impacts. Science 289:2068-2074

Fan L, Xiong Z (2015) Using quantile regression to detect relationships between large-scale predictors and local precipitation over northern China. Adv Atmos Sci 32(4):541-552

Frich P, Alexander LV, Della-Marta P, Gleason B, Haylock M, Klein Tank A, Peterson T (2002) Observed coherent changes in climatic extremes during the second half of the twentieth century. Clim Res 19:193-212

Gao M, Mo D, Wu X (2016) Nonstationary modeling of extreme precipitation in China. Atmos Res 182:1-9 
Gong DY, Wang SW (2003) Influence of Arctic Oscillation on winter climate over China. J Geogr Sci 13(2):208-216

Huang Y, Wang HJ, Fan K, Gao YQ (2015) The western Pacific subtropical high after the 1970s: westward or eastward shift? Clim Dyn 44:2035-2047

Hurrell JW, Deser C (2010) North Atlantic climate variability: the role of the North Atlantic oscillation. J Mar Syst 79:230-230

IPCC (2007) Climate change 2007: the physical science basis. contribution of working group I to the fourth assessment report of the intergovernmental panel on climate change. Cambridge University Press, Cambridge

IPCC (2012) Special report on managing the risks of extreme events and disasters to advance climate change adaptation. A report of working groups I and II of the intergovernmental panel on climate change. Cambridge University Press, Cambridge

Jahanbaksh Asl S, Khorshiddoust AM, Dinpashoh Y, Sarafrouzeh F (2011) Frequency analysis of climate extreme events in Zanjan, Iran. Stoch Environ Res Risk Assess 27:1637-1650

Jones PD, Lister DH, Li Q (2008) Urbanization effects in large-scale temperature records, with an emphasis on China. J Geophys Res 113:D16122

Kalnay E, Kanamitsu M, Kistler R et al (1996) The NCEP/NCAR 40-year reanalysis project. Bull Am Meteorol Soc 77(3):437-471

Katz R (2010) Statistics of extremes in climate change. Clim Change 100:71-76

Katz R (2013) Statistical methods for nonstationary extremes. In: Easterling D, Hsu K, Schubert S, Sorooshian S, AghaKouchak A (eds) Extremes in a changing climate. Springer, Berlin, pp 15-38

Koenker RW, Bassett G Jr (1978) Regression quantiles. Econometrica 46:33-50

Koenker RW (2005) Quantile regression. Cambridge University Press, Cambridge

Khaliq MN, Ouarda TBMJ, Ondo JC, Gachon P, Bobee B (2006) Frequency analysis of a sequence of dependent and/or nonstationary hydro-meteorological observations: a review. J Hydrol 329:534-552

Kharin VV, Zwiers FW (2005) Estimating extremes in transient climate change simulations. J Clim 18:1156-1173

Kharin VV, Zwiers FW, Zhang X, Hegerl GC (2007) Changes in temperature and precipitation extremes in the IPCC ensemble of global coupled model simulations. J Clim 20:1419-1444

Kharin VV, Zwiers FW, Zhang X, Wehner M (2013) Changes in temperature and precipitation extremes in the CMIP5 ensemble. Clim Change 119:345-357

Kiem AS, Franks SW, Kuczera G (2003) Multi-decadal variabilityof flood risk. Geophys Res Lett 30(2):GL015992

Kim H, Kim S, Shin H, Heo J (2017) Appropriate model selection methods for nonstationary generalized extreme value models. J Hydrol 547:557-574

Leadbetter MR (1983) Extremes and local dependence in stationary sequences. Probab Theory Relat Fields 65(2):291-306

Li Z, Brissette F, Chen J (2013) Finding the most appropriate precipitation probability distribution for stochastic weather generation and hydrological modelling in Nordic watersheds. Hydrol Process 27(25):3718-3729

Milly PCD, Betancount J, Falkenmark M, Hirsch RM, Kundzewicz ZW, Lettenmaier DP, Stouffer RJ (2008) Stationarity is dead: Whither water management? Science 319:573-574

Olsen JR, Lambert JH, Haimes YY (1998) Risk of extreme events under nonstationary conditions. Risk Anal 18(4):497-510

Panagoulia D, Economou P, Caroni C (2014) Stationary and nonstationary generalized extreme value modelling of extreme precipitation over a mountainous area under climate change. Environmetrics 25:29-43
Parey S, Malek F, Laurent C, Dacunha-Castelle D (2007) Trends and climate evolutions: Statistical approach for very high temperatures in France. Clim Change 81:331-352

Parey S, Hoang TTH, Dacunha-Castelle D (2010) Different ways to compute temperature return levels in the climate change context. Environmetrics 21:698-718

Ramos AM, Lorenzo MN, Gimeno L (2010) Compatibility between modes of low-frequency variability and circulation types: a case study of the northwest Iberian Peninsula. J Geophys Res 115:D02113

Robeson SM, Willmott CJ, Jones PD (2014) Trends in hemispheric warm and cold anomalies. Geophys Res Lett 41(24):9065-9071

Rootén H, Katz RW (2013) Design life level: quantifying risk in a changing climate. Water Resour Res 49(9):5964-5972

Salas JD, Obeysekera J (2014) Revisiting the concepts of return period and risk for nonstationary hydrologic extreme events. J Hydrol Eng 19:554-568

Shiau J, Huang W (2015) Detecting distributional changes of annual rainfall indices in Taiwan using quantile regression. J Hydroenvironment Res 9:368-380

Siliverstovs B, Ötsch R, Kemfert C, Haeger CC, Haas A, Kremers H (2010) Climate change and modelling of extreme temperatures in Switzerland. Stoch Environ Res Risk Assess 24:311-326

Tan X, Shao D (2017) Precipitation trends and teleconnections identified using quantile regressions over Xinjiang, China. Int J Climatol 37(3):1510-1525

Tareghian R, Rasmussen PF (2012) Analysis of Arctic and Antarctic sea ice extent using quantile regression. Inter $\mathrm{J}$ Climatol 33:1079-1086

Tebaldi C, Hayhoe K, Arblaster JM, Meehl GA (2006) Going to the extremes: an intercomparison of model-simulated historical and future changes in extreme events. Clim Change 79:185-211

Thompson DWJ, Wallace JM (1998) The Arctic oscillation signature in the wintertime geopotential height and temperature fields. Geophys Res Lett 25:1297-1300

Villarini G, Serinaldi F, Smith JA, Krajewski WF (2009) On the stationarity of annual flood peaks in the continental United States during the 20th century. Water Resour Res 45(8):W08417

Wang SW, Gong DY (2000) Enhancement of the warming trend in China. Geophys Res Lett 27:2581-2584

Wi S, Valdés JB, Steinschneider S, Kim TW (2016) Non-stationary frequency analysis of extreme precipitation in South Korea using peaks-over-threshold and annual maxima. Stoch Environ Res Risk Assess 30:583-606

Wigley TML (1988) The effect of climate change on the frequency of absolute extreme events. Clim Monit 17:44-55

Wigley TML (2009) The effect of changing climate on the frequency of absolute extreme events. Clim Change 97:67-76

Wu R, Hu ZZ, Kirtman BP (2003) Evolution of ENSO-related rainfall anomalies in East Asia. J Clim 16:3742-3758

Wu Y, Liu Y (2009) Stepwise multiple quantile regression estimation using non-crossing constraints. Stat Interface 2:299-310

Xu X, Du Y, Tang J, Wang Y (2011) Variations of temperature and precipitation extremes in recent two decades over China. Atmos Res 101:143-154

You QL, Kang SC, Aguilar E, Pepin N, Flügel WA, Yan YP, Xu Y, Zhang YJ, Huang J (2011) Changes in daily climate extremes in China and their connection to the large scale atmospheric circulation during 1961-2003. Clim Dyn 36:2399-2417

You QL, Fraedrich K, Min J, Kang S, Zhu X, Ren G, Meng XC (2013) Can temperature extremes in China be calculated from reanalysis? Global Planet Change 111:268-279

Yu K, Lu Z, Stander J (2003) Quantile regression: application and current research areas. Statistician 52:331-350

Zhai P, Pan XH (2003) Trends in temperature extremes during 1951-1999 in China. Geophys Res Lett 30:1913 
Zhang Q, Li J, Chen Y, Chen X (2011) Observed changes of temperature extremes during 19602005 in China: natural or human-induced variations? Theor Appl Climatol 106(3):417-431

Zhang X, Zwiers FW (2013) Statistical indices for the diagnosing and detecting changes in extremes. In: Easterling D, Hsu K, Schubert
S, Sorooshian S, AghaKouchak A (eds) Extremes in a changing climate. Springer, Berlin, pp 1-14

Zhou Y, Ren G (2011) Change in extreme temperature event frequency over mainland China, 1961-2008. Clim Res $50: 125-139$ 